\title{
MUSEOLOGIA E ACERVOS PARTICULARES: O CASO DAS FAMÍLIAS DA CHACINA DE BELÉM.
}

Andrey LEÃO ${ }^{1}$

Hugo MENEZES NETO ${ }^{2}$

\section{Resumo}

O presente texto visa investigar como famílias que perderam seus filhos lidam com os objetos que pertenciam a esses entes queridos. Sabendo que muitas dessas famílias optam por guardar, ou por manter expostos tais objetos, a pesquisa se interessa pelas representações e sentidos a eles atribuídos, bem como pelas motivações, sentimentos e intuitos por trás do ato de transformá-los em objetos expositivos, dispostos em quartos e outros cômodos da casa, ou do ato de salvaguardá-los em armários e gavetas, como acervos de acesso restrito aos parentes. Interessa-se, por conseguinte, pelo movimento contínuo de seleção, manutenção, manuseio e ressignificações desses objetos, numa perspectiva de musealização particular que tangencia enlutamento, privacidade e intimidade.

\begin{abstract}
The present text aims to investigate how families that lost their children deal with the objects that belonged to these loved ones. Knowing that many of these families choose to keep, or keep exposing such objects, research is interested in the representations and meanings attributed to them, as well as the motivations, feelings and intentions behind the act of transforming them into expository objects, arranged in rooms and other rooms of the house, or the act of safeguarding them in closets and drawers, as collections of restricted access to relatives. It is therefore interested in the continuous movement of selection, maintenance, handling and re-signification of these objects, in a perspective of particular musealization that touches on engagement, privacy and intimacy
\end{abstract}

\section{INTRODUÇÃO}

Em Belém do Pará, no dia 4 de novembro de 2014, o policial militar afastado de seu cargo, Antônio Marco da Silva Figueiredo, conhecido por Cabo Pet, foi abordado por volta das 19 horas perto de sua casa, no bairro do Guamá, por três homens que o alvejaram com 30 tiros. Logo após o acontecido, que resultou na morte do cabo, mensagens em redes sociais como o Facebook, Twitter e Whatsapp, começaram a circular convocando outros policiais para vingar a morte e instaurando um toque de recolher na cidade, especialmente para os moradores dos bairros da periferia. A ameaça foi cumprida e grupos de homens encapuzados

\footnotetext{
${ }^{1}$ Museólogo, bacharel em Museologia pela Universidade Federal do Pará (UFPA). Bolsista PIBIC no Projeto "Patrimônios afetivos e acervos familiares: reflexões antropo-museológicas sobre morte, luto e objetos", que investigou a chacina.

${ }^{2}$ Professor do Departamento de Antropologia e Museologia da Universidade Federal de Pernambuco. Professor do Programa de Pós-graduação em Antropologia da Universidade Federal de Pernambuco. Professor colaborador do Programa de Pós-graduação em Antropologia da Universidade Federal do Pará. Coordenador do projeto "Patrimônios afetivos e acervos familiares: reflexões antropo-museológicas sobre morte, luto e objetos" E-mail: hugonetto0@gmail.com
} 
em motos e carros de cores preta e/ou prata executaram sumariamente 10 jovens, em diferentes comunidades,morreram os que desobedeceram a ordem. As ações decorrentes de tais fatos ficaram conhecidas como Chacina de Belém³ ${ }^{3}$

A Chacina de Belém começou na noite do dia 4, logo depois da circulação das mensagens, e se estendeu entre a madrugada até a manhã do dia 5 . O evento trágico foi provocado por componentes de grupos de milícias, policiais e ex-policiais militares, que circularam amedrontando e atirando em vítimas de um perfil específico: jovens, do sexo194 masculino, negros, que desobedeceram o toque de recolher. O evento contabilizou 11 mortes no total(incluindo a do cabo). Quem não estava na rua, ou conseguiu correr, escapou da morte: "Eles chegaram atirando. Muitos que estavam no churrasco correram para dentro de sua casa que estavam próximas, ele resolveu correr para casa do meu filho, também era perto, só que eles acabaram seguindo ele, atirando" (Vanda, irmã de Alersonvaldo, uma das vítimas).

Apesar de ter ocorrido nas periferias de Belém, notícias e boatos foram recebidos por meio de redes sociais aos moradores de toda a cidade, fazendo com que a totalidade e gravidade do evento afetassem grande parte da população ${ }^{4}$. Muito se falava sobre o envolvimento do Cabo Pet em grupos de milícias cuja atuação nas comunidades mais pobres é notória. Com a pressão dos movimentos sociais que encamparam uma campanha junto com os familiares das vítimas, foi instaurada a CPI das milícias.No relatório sobre a Chacina foi confirmada a existência de cinco grupos de milícias que atuam no estado do Pará; o Cabo Pet era líder de uma delas. Também foi confirmada pela CPI que nenhuma vítima teve envolvimento com a morte do Cabo, nem teriam passagem pela polícia, contrariando as versões difundidas pela imprensa e pelo poder público de que se tratava de "bandidos". Conforme consta no relatório:

\begin{abstract}
A instauração da Comissão Parlamentar de Inquérito que apura a atuação de milícias e grupos de extermínio no Estado do Pará, é fruto da indignação da Sociedade Paraense ante aos acontecimentos que sucederam ao homicídio do Policial Militar afastado de suas funções CB PM Antonio Marco da Silva Figueiredo, conhecido por Cabo PET, morto em emboscada no bairro do Guamá, com 20 tiros, às 19h do dia 04 de novembro, desencadeando uma madrugada de matança indiscriminada, que deixou o saldo de 11 (onze) corpos na manhã do dia 05 de dezembro. (PARÁ, 2015).
\end{abstract}

\footnotetext{
${ }^{3}$ (LOUREIRO; FERREIRA JUNIOR; COSTA, 2015)

${ }^{4}$ Dados da CPI das Milícias. 
Durante a manifestação para lembrar 1 ano da Chacina (ato que fez uma grande passeata na Avenida de Magalhães Barata, com saída da Praça do Centro Arquitetônico de Nazaré, terminando no Mercado de São Brás), na qual estivemos presente, uma mãe estava com a farda de trabalho do filho em mãos quando uma repórter local a chamou para fazer uma entrevista.A mãe balança a farda do filho e chorava ao mesmo tempo, falava que seu filho era inocente e trabalhador. Naquele momento aquela farda era para a mãe a prova de tudo o que ela dizia. A partir de exemplos como esse, nos interessamos em pesquisar como as famílias 195 que perderam seus filhos em decorrência da violência urbana lidam com os objetos que pertenciam a esses entes queridos e como a Chacina interfere na constituição dos seus acervos familiares. Por conseguinte, interessávamospelo movimento contínuo de seleção, manutenção, manuseio e ressignificações desses objetos, desse acervo afetivo.

Partimos de dois eixos centrais: que a Museologia tem como problemaidentificar e analisar a relação individual e/ou coletivo da humanidade com a realidade,que em certa medida,resulta na coleção e na conservação consciente e sistemática, e na utilização científica, cultural e educativa, de objetos inanimados, materiais, móveis (sobretudo tridimensionais) que documentam o desenvolvimento da natureza e da sociedade (Gregorová, 1980); e que a museologia devetambém estudar as performances feitas pelas pessoas com seus objetos (Brulon, 2014). Assim, a museologia, em diálogo mais profícuo com a antropologia podem pensar os usos, transformações e deslocamentos que os objetos fazem em contextos sociais, cerimoniais, institucionais, discursivos, e também domésticos, compreendendo que, no escopo da categoria patrimônioé possível entender a própria dinâmica da vida social e cultural, seus conflitos, ambiguidades e paradoxos, assim como seus efeitos na subjetividade individual e coletiva (Gonçalves, 2007). Logo, a musealização dos objetos deixados pelos jovens mortos na Chacina de Belém, sua transformação em acervo de um patrimônio afetivo familiar, para além de lembranças, tem muito a dizer sobre a experiência da periferia, tem potencial para uma crítica à força da violência urbana na vida de grupos socialmente desassistidos pelo estado e morto pelo próprio estado.

Lançando mão de estratégicas metodológicas da Antropologia para produção de dados e análise, entramos em contato com as famílias, acompanhamos suas manifestações públicas em busca por justiça, visitamos suas casas e realizamos entrevistas semiestruturadas com 
quatro delas ${ }^{5}$, tentando entendera seleção, o descarte, a salvaguarda e a exposição dos objetos pela casa.

\section{APRESENTANDO AS FAMÍLIAS E OS OBJETOS.}

2.1 Vítima da Chacina: Arlesonvaldo Mendes (Jarrão), 37 anos.

Vanda(Irmã da irmâ) e David(Cunhado).

Bairro do acontecido: Marco.

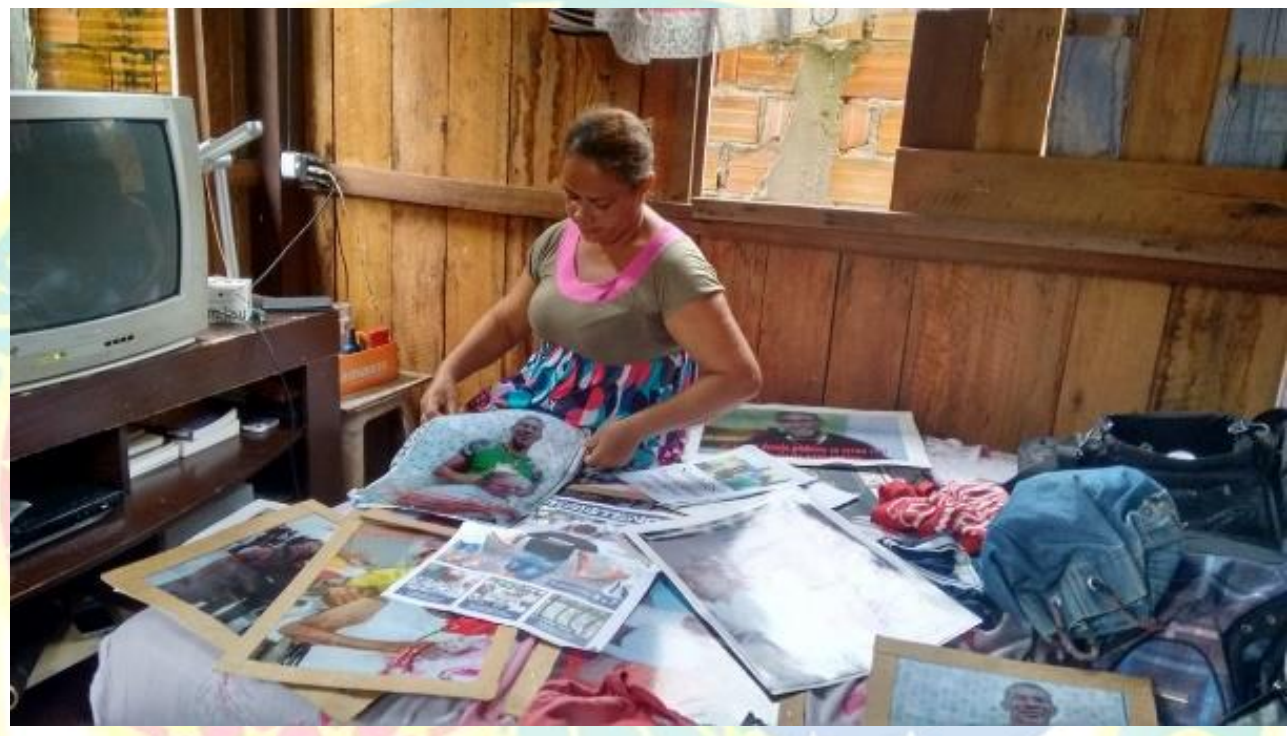

Figura 1 - Vanda com os objetos do Irmão.

A primeira entrevista foi feita com a família de Arlesonvaldo Mendes, apelidado de Jarrão. Os entrevistados foram o casal Vanda e David, respectivamente irmã e cunhado da vítima. Eles são moradores do bairro do Marco, local onde Alersonvaldo foi baleado, e vivem em uma pequena casa de madeira com apenas 2 cômodos no fundo de um terreno de família.

Jarrão tinha um problema cognitivo, uma pessoa de 37 anos com mentalidade de uma criança de 12, inclusive ainda cursando o ensino fundamental. Apesar de Jarrão morar com a mãe, Vanda tomou a frente da militância por justiça, já que os outros familiares não podiam e, para ela, é um modo de ficar "resolvida" com seu irmão:

\footnotetext{
${ }^{5} \mathrm{Na}$ segunda parte da pesquisa, durante a realização das entrevistas semi-estruturadas, juntou-se ao projeto o Núcleo de Experimentação Cinematográfica(NEC) do curso de Cinema da UFPA, com intuito de criarmos, juntos, um Documentário sobre o evento e a relação dos familiares com objetos pertencentes as vítimas. O documentário intitulado de "É o Que Eu Guardo Dele", foi exibido para os familiares das vítimas, e com o aval dos mesmos, houve a divulgação do trabalho.
} 


\begin{abstract}
Não queria que minha mãe estivesse na frente, ela não iria aguentar. Ela só de ver a situação da morte do meu irmão, ela já ficou abatida. Ela não vive, ela sobrevive.(...) Não tinha como deixar ela na frente. Os meus outros irmãos, eles trabalham. Tinha que ser uma pessoa que tivesse disponível pra lutar. Então disse assim: 'Então eu vou!'” (Vanda).
\end{abstract}

Muitos dos objetos que pertenceram à vítima estão na casa de Vanda(figura 1). As roupas nãoselecionadas para salvaguarda foram doadas para os irmãos, outros objetos foram doados para amigos e professores que gostavam dele.Após a morte de Jarrão, Vanda mexeu 197 no guarda roupa do irmão e encontrou uma Bíblia, dentro dela havia uma foto de seu casamento com David. Para ela foi impactante, pois não sabia que o irmão guardava a foto, e percebeu um ato de afeto para com a família, e cuidado com as suas coisas. Para a mãe de Jarrão foi difícil se desfazer, descartar,as coisas dele, foi um momento de entender definitivamente que ele não estava mais lá.Somos constituídos de materialidade, logo, as roupas para a mãe da vítima, ainda eram uma parte dele. A mãe ficou com uma camisa, algumas fotos e uma bermuda.

Os familiares das vítimas da Chacina, junto com o grupo Tela Firme, fizeram uma exposição itinerante intitulada de Choram os Cravos do Novembro que percorre os lugares de Belém com objetos das vítimas reivindicando justiça. Os objetos de Jarrão que vão para a exposição são algumas cartas de amigos da Igreja, uma camisa verde escrita "Exercito de Deus", seu uniforme escolar e alguns cartazes com fotos da vítima feitos depois de sua morte.

Como a casa de Vanda e David é um pequeno imóvel com 2 cômodos, as roupas de Jarrão ficam no guarda roupa da família. Acessadas apenas quando necessário, "É difícil tocar no nome dele, até mesmo olhar as coisas dele, porque vem toda a lembrança novamente"(Vanda).As cartas remetidas pelos amigos, um CD evangélico que ele escutava e algumas fotos antigas, estão guardadas em uma escrivaninha onde fica a Televisão. Nota-se que os objetos que exaltam que a vítima era uma pessoa da igreja e querida por amigos, foram guardados com sentido de demonstrar que ele era um "cidadão de bem", diferindo da visão que os familiares acusaram a mídia de impor.

Grande parte das fotos de Jarrão foi digitalizada para melhor salvaguardá-las, e ficam armazenadas no notebook de David. Algumas delas foram impressas e colocadas em cartazes, juntos com recortes de matérias jornalísticas sobre a Chacina e em Banners feitos para os eventos públicos da militância por justiça que sistematicamente as famílias realizam.Algumas fotos e banners ficam expostos pela casa, outros guardados. No notebook de David são 
guardadas também prints de notícias online sobre o caso, uma espécie de dossiê. Apesar desses objetos não conviverem com Jarrão, eles têm o mesmo cuidado e importância para os familiares.

Meneses (1998) diz que um objeto que contêm informação torna-se documento, por isso, por serem fontes informacionais sobre a inocência da vítima, para as famílias esses objetos são documentos que atestam contra essa visão da mídia. Os objetos exaltam a vítima, provando que se tratava de uma pessoa religiosa e querida por amigos. São testemunho, 198 fragmentos do passado que (re)criam um nexo (Seligmann-Silva, 2005), uma história, reforça o que deve ser a memória de um evento (Halbwachs, 2013).

Vanda providenciou o atestado de antecedentes criminais do irmão, e o guarda como prova do não envolvimento do irmão em irregularidades criminais. A experiência da vida na periferia, da convivência direta com a violência urbana, e a desconstrução dos estereótipos de moradores desses bairros é um tema recorrente que permeia os objetos:

O governador simplesmente até hoje nunca sequer chegou com as famílias pra conversar. O que ele fez foi, no mesmo dia, dizer que estavam na hora errada: 'local de periferia, tinha que tá dentro de casa', ou seja, só porque nós moramos em periferia, somos bandidos. Porque somos pobres e temos necessidade de estar roubando, isso que ele quis dizer. Enquanto o pessoal lá da elite, não. Eles podem andar a hora que quiser na rua. A gente não podemos. (David).

Devido a isso, os familiares das vítimas da Chacina, junto com o grupo Tela Firme, fizeram uma exposição itinerante intitulada de Choram os Cravos do Novembro, que percorre os lugares de Belém com objetos das vítimas reivindicando justiça. Os objetos de Jarrão que vão para a exposição são as cartas dos amigos da Igreja, a camisa verde escrita "Exercito de Deus", seu uniforme escolar e alguns cartazes com fotos da vítima feitos depois de sua morte. Esses objetos foram selecionados por apresentar outro perfil das vítimas, diferentes daquelemostrada pela mídia e pelo poder público.

2.2 Vítima da Chacina: Bruno Gemaque, 17 anos.

Meire(tia) e Andréia(Mãe).

Bairro do acontecido: Terra Firme.

Encontramos a família de Bruno Gemaque, 17 anos, sua tia Meire (com quem ele morava) e Andréia, a mãe. A conversa se deu na casa de Meire(figura 3), na periferia de Belém, bairrono qual o Bruno foi assassinado e onde morou durante a adolescência até sua morte prematura.Na versão delas, Bruno foi buscar sua namorada na escola quando foi 
abordado por cindo homens encapuzados em motos, que o puxaram da bicicleta e o mataram sem dá oportunidade do jovem falar alguma coisa. Logo depois, mandaram a sua namorada, que presenciou tudo, ir embora sem olhar para trás. A tia estava em casa quando ouviu os tiros, e logo após, seu filho chegou anunciando que atiraram no Bruno. A mãe chegou um dia depois do evento, quando o corpo já estava no Instituto Médico Legal.

Na descrição dos familiares, Bruno era alegre, bondoso e trabalhador. Trabalhava em no transporte alternativo de passageiros. Desistiu dos estudos, pois não conseguiu conciliar 199 com o trabalho, mas pretendia voltar para escoa em breve. Meire é a pessoa da família que encampou a militância, comparece aos atos, aos julgamentos e outras ações que reivindicam justiça.

Como a vítima tinha duas casas, a da mãe, no interior do Pará, onde ele morou quando criança, e a casa em Belém onde morou quando adolescente até sua morte, os objetos ficam divididos nesses dois polos. Andréia, a mãe, tem roupas, fotos e objetos pessoais que ele deixou no interior. Essas coisas ficam sob sua tutela e ela decidiu o destino depois da morte. Andréia relata que algumas coisas de lá foram doadas para o primo da vítima, e que guarda poucas coisas, aquelas que mais a faz lembrardele.

Meire também diz guardar poucas coisas; o que era trivial, de uso, foi doado para outro sobrinho por ter o mesmo tamanho da vítima. Ela guardou algumas roupas, aquelas de maior identificação com a vítima (Stalybrass, 2009), documentos e fotos.Nota-se que nesse caso, a doação dos objetos tem a ver com a funcionalidade e a necessidade dos familiares vivos, ainda assim quem herdou era alguém que gostava muito de Bruno, é até fisicamente semelhante a ele. Há, portanto, a escolha de a quem doar porque não se trata de coisas qualquer.

Na casa de Meire, na sala, tem uma estante com fotos e cartazes do Bruno.A casa é um espaço privilegiado e sacralizado para exposição desses objetos dotados de narrativas, constituintes e testemunhos da história da vítima e da Chacina. Outrosobjetos ficam na gaveta do guarda roupa de Andréia, e são acessados só para fazer limpeza: "De vez em quando, quando eu vou limpar o guarda roupa, eu limpo. Tiro de lá, dobro de novo, coloco lá”.

Meire relata que rever as fotos de Bruno com frequência, para lembrar do sobrinho. Mas, prefere as fotos da infância, as mais recentes ficam guardadas fora do alcance, pois, vêlas “é mais doloroso". Como diz Miriam Moreira Leite (1993, p. 137), “a leitura da imagem é feita a partir de experiências acumuladas anteriores que se desdobram na memória, diante da 
imagem presente". A imagem de Bruno adolescente, então, está ligada a experiências da Chacina, ainda suscitam o evento, enquanto que a imagem dele quando criança está ligada a uma experiência familiar. Como exceção, tem fotos recentes de Bruno na sala da casa de Meire, numa estante, em um porta-retrato e alguns cartazes (produzidos para a militância). A casa é um espaço para expor esses objetos, uma espécie de exposição particular que conta um pouco da personalidade da vítima e do evento trágico.

Assim como a família de Arlesonvaldo, a família de Bruno também fala na entrevista200 como a mídia e a sociedade tratam o caso e sobre violência urbana, principalmente na periferia:

E a gente hoje em dia sente muita revolta de alguns apresentadores, né. E principalmente do governo que não fez nada, e não tá fazendo nada por isso, ne. Se a gente tamo chegando até onde a gente tamo, é esforço nosso. E então, assim, a gente fica muito revoltado com isso, ne, de tarem sujando a imagem da nossa família, dele, ne.(...) Tem apresentador que fala: 'Ah! Porque depois que morre vira santo', mas não é o caso, é porque ele não era a pessoa que eles falam que é, né. (...). Mas podem procurar em qualquer canto, em qualquer delegacia, que meu filho não tinha passagem pela polícia. Ele não tinha. Então pra gente é muito duro. (...). É constante. Aconteceu a chacina, mas isso não parou. Continua ainda, né. Continua matando jovens da periferia. Pessoas pobres, né. Pessoas negras. E jovens que na maioria são trabalhadores. Ás vezes não deve nada pra polícia. Não deve nada pra justiça. (Meire)

Para exposição realizada junto com o grupo Tela Firme, Meire leva as roupas que ele mais usava e alguns cartazes feitos com fotos da vítima adolescente, nome da vítima, algumas frases e símbolo do time que lembram Bruno. Meire disse que a exposição teve muita repercussão e isso foi muito bom, já que via muita gente reconhecendo o sobrinho através de seus pertences e que nem sabiam que ele tinha morrido. Esses visitantes, segundo ela,ratificavam que a vítima era uma pessoa boa,sem relação com o crime, atestando a narrativa da família e potencializando os objetos. 


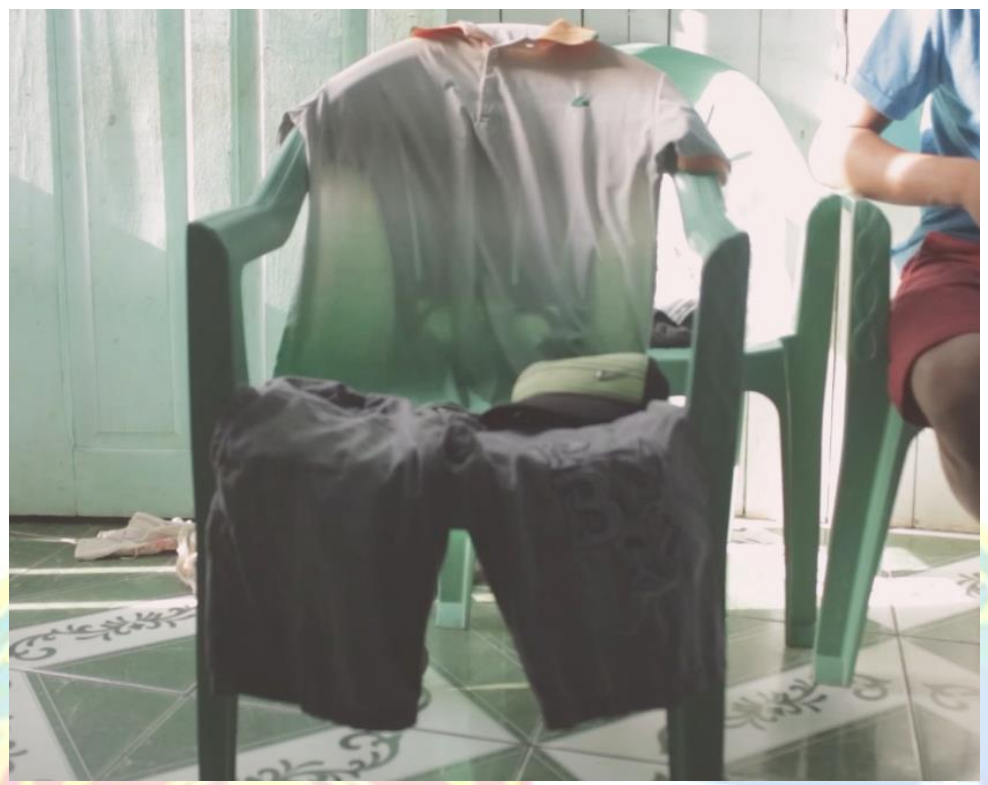

Figura 4 - Roupas de Bruno.

Fonte: Andrey Leão

\subsection{Auxiliadora(Avó)}

Vítima da Chacina: Eduardo Galúcio Chaves, 16 anos.

Bairro do acontecido: Terra Firme.

De acordo com a versão de Dona Auxiliadora, avó de Eduardo, seu neto, criado por ela como um filho, estava perto de sua casa, tinha ido fazer compras com a namorada quando homens em motos chegaram e o mataram. Dona Auxiliadora ouviu os tiros correu para saber de seu neto mas, já encontrou o corpo da vítima no chão.

Dona Auxiliadora diz que ele era uma pessoa muito meiga, era "seu companheiro" para as atividades do dia-a-dia. Continua dissertando, era inteligente, trabalhador, não era consumista, mas sabia da precária situação financeira da família. Começou a trabalhar bem jovem para ajudar em casa e ter as coisas que queria. Trabalhava fazendo entregas, vendia churrasco nos fins de semana na rua, em frente de casa, e cultivava o sonho de ser marinheiro ou polícia militar.

Dona Auxiliadora guarda muitas coisas do neto, desde que ele nasceu. Parte desse acervo diz respeito à infância de Eduardo, como seu umbigo, os boletins escolares, roupas de criança, farda de escoteiro, fotos; outra parte é coisas mais recentes, documentos, instrumentos musicais (pandeiro e flauta), Bíblia, fotos atuais, celular e outros. Depois da morte de Eduardo, Auxiliadora não se descartou de muita coisa. Doou algumas roupas, 
ficando apenas com as que ele usava para dormir, para, por vezes, colocar em cima da cama e lembrar do neto arrumado, pronto para dormir. A memória se faz na ação, nos gestos (Nora, 1993), no caso, na recriação da cena como forma de presentificar o neto. O acervo da infância é ressignificado após a chacina, uma vez que, para ela, os boletins com boas notas e a farda de escoteiro, por exemplo, "mostram que o neto não foi bandido, sempre estudou".

Dona Auxiliadora também doou o seu vestido que usava no dia da Chacina, pois o fazia lembrar de tudo o que aconteceu no dia do evento, como ela diz. LembrandoStallybrass 202 (2000), o objeto está impregnado de memória, contudo, nesse caso, como o objeto pertencia a ela, ele não lembra o neto, apenas remete a memória dolorosa da Chacina.

Como uma curadora, ela sabe onde está tudo. Boa parte fica no quarto que seria de Eduardo, ainda em construção. No guarda-roupa ficam guardados principalmente as fotos e os documentos. Todos em pastas a seu modo organizadas. É uma forma de ter controle do acervo. Os objetos, são acessados frequentemente para lembrar do neto, principalmente as fotos, servindo para uma narrativa familiar.

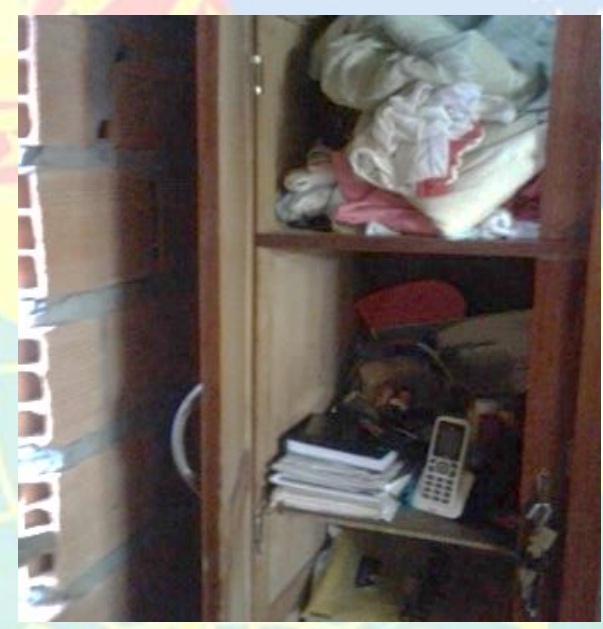

Figura 5

Guarda-roupa onde são guardadas as coisas de Eduardo. Fonte: Andrey Leão.

Como dito, Eduardo fazia parte dos escoteiros e tinha um uniforme com emblemas do grupo. A professora de Eduardo pediu que Auxiliadora doasse o uniforme, mas a avó se recusou, doou somente os emblemas. O mesmo procedimento foi feito com as flautas de Eduardo. Para que não ficassem guardadas, algumas flautas foram doadas, restando apenas uma, a mais cara. Nesse caso, as flautas, junto com um pandeiro, representavam a mesma memória de Eduardo, sobre seu dom musical. Por isso, descartou as outras flautas, já que havia mais de um objeto que demostrava a mesmo qualificativo positivo sobre o neto. 
Também foi guardado a Bíblia de Eduardo, já que, segunda a avó, ele era evangélico e "nunca deixava de dar o dízimo".

Esses objetos atestam qualidades de Eduardo, ele seria religioso, bom aluno, escoteiro, dizimista, com talentos musicais, trabalhador, tinha uma namorada e amigos na comunidade; características opostas à ideia de bandido.

Auxiliadora, assim como as outras famílias entrevistadas, também reflete sobre violência urbana: "Porque estamos nesse Pará aqui, nesse mundo aqui, nós não sabemos 203 quando a gente sai, não sabemos mais se volta, se entra dentro de casa. Não pode ficar na frente de casa. Não pode mais colocar uma venda, porque a hora e momento nós estamos sendo morto por essas pessoas" (Auxiliadora).

Auxiliadora guarda o celular da vítima, mas antes de o ter no acervo, a polícia fez perícia com todos os equipamentos dos jovens assassinados, numa investigação para encontrar relações com o crime: "Ninguém quis levar no dia, que jogaram lá perto dele. Eu tenho o chip e isso aqui (celular). Passou uma semana, um mês na mão da polícia. Eu dei porque o meu filho não era ladrão. Deixei pra eles fazerem perícia. E eu guardo ele" (Auxiliadora). O celular, assim como o atestado criminal de Alesonvaldo, guardado por sua irmã, Vanda, é fonte informacional, e consequentemente, documento (MENESES, 1998).

No dia da entrevista, os objetos da exposição Choram os Cravos do Novembro, um manequim com marcas de balas, alguns cartazes produzidos pelas famílias, recortes de jornais com reportagens sobre a Chacina, e um banner grande com fotos de todas as vítimas, usados tanto na exposição como em protestos, estavam depositados em um quarto desocupado, à espera da próxima manifestação em ocasião, o julgamento de um dos policiais envolvidos no caso. Esses objetos sairiam da casa da Auxiliadora para frente do fórum, onde as famílias protestariam em busca de justiça.Auxiliadora relata que abraçava o manequim para lembrar do neto. Os objetos coletivos e individuais se misturam, relatam particularidades de cada vítima, mas também a experiência compartilhada Maurice Halbwachs(2013), a tragédia, a vivência da periferia comum aos jovens negros e pobres das grandes cidades.A rememoração pessoal está situada na encruzilhada das redes de solidariedade múltiplas em que estão envolvidos, ou seja, os acervos domésticos produzidos de forma particular pelas famílias endossam/expressam/narram memórias coletivas. 


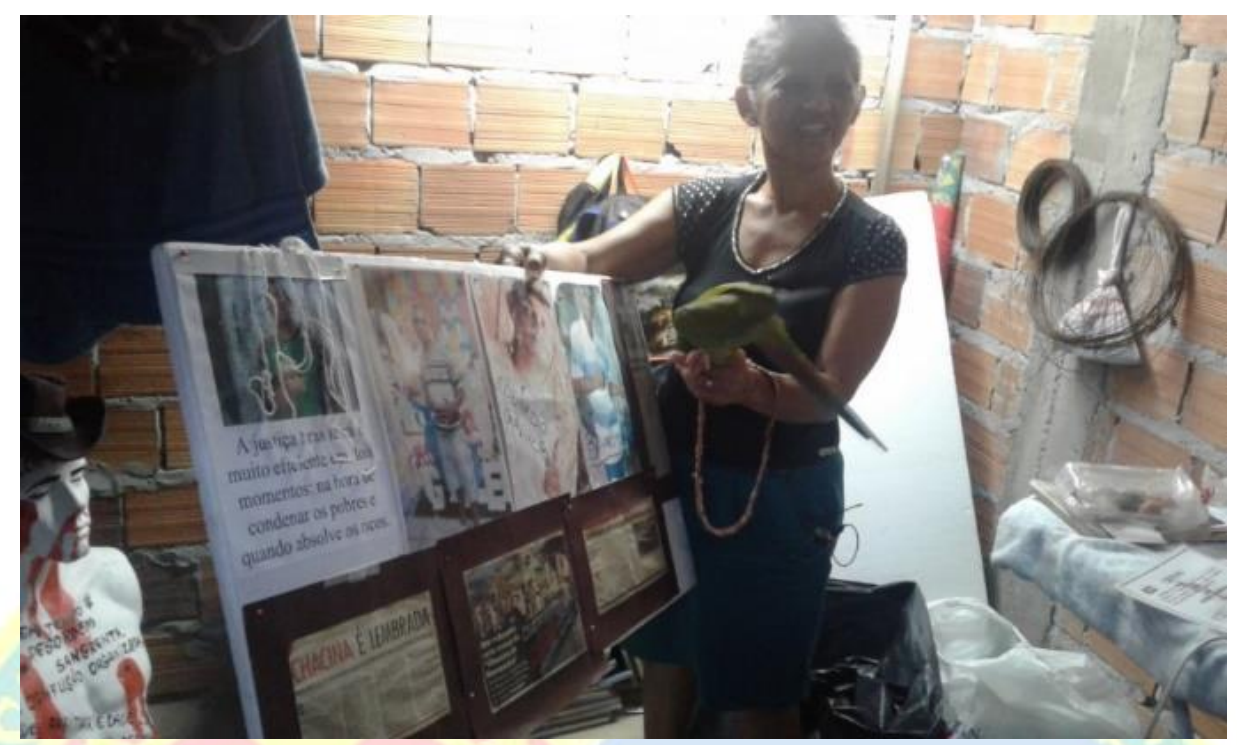

Figura6 - Cartazes que vão para a exposição, junto como manequim no canto inferior esquerdo da foto. Fonte: Andrey Leão.

Suzana (Mãe da Vítima)

Vítima da Chacina: Márcio Rodrigues, 22 anos.

Bairro do acontecido: Tapanã.

Márcio chegava do trabalho com dois amigos em uma moto por volta da 01 hora da manhã, no bairro Tapanã, onde seus avós moram. Cruzaram com duas motos no caminho, os motociclistas o seguiram, e na porta da casa de seus avós foram alvejados. Márcio foi o único atingido e morreu na hora.

A vítima trabalhava em uma churrascaria na Av. Doca de Souza Franco, local considerado como de elite na cidade de Belém, onde, de acordo com a sua mãe, Suzana, "pobre só vai se for empregado". Também de acordo com ela, o filho não sabia dos boatos que estavam sendo divulgados pelas redes sócias, pois, ao entrar na Doca, ele não estava mais em seu mundo, não sabia nada o que acontecia na periferia. Algumas câmeras próximas ao local do acontecido filmaram as motos perseguindo Márcio e seus amigos. As filmagens posteriormente foram divulgadas nos jornais locais.

Suzana relata seu filho como um rapaz de muitos amigos, bondoso, trabalhador, alegre e "moleque". Frequentador assíduo das festas da periferia da cidade. Gostava da aparelhagem Búfalo do Marajó. Márcio formava com seus amigos o grupo conhecido como Os Megas Camaradas, que marcava presença nas festas de aparelhagem para beber cerveja, dançar e se divertir. Os Megas Camaradas, ressalta Suzana, também fazia eventos sociais com crianças do 
bairro. Márcio era conhecido como Marcinho Pitbull, por usar roupas da marca Pitbull. Ele cursava administração, mas queria fazer gastronomia.

Suzana foi a responsável por mobilizar as outras mães, em busca de respostas. Pegou o jornal cuja matéria principal trazia um mapa com os locais das mortes dos jovens, apenas o nome dos bairros, sem as ruas. Ela, então, investigou e procurou cada uma das outras famílias que sofreram com a Chacina, vencendo o medo, a lei do silêncio e as ameaças por parte dos milicianos.

Após a morte do filho, Suzana chamou os amigos e disse para eles levarem o que quisessem, e o que sobrasse ela iria guardar. Antes, porém, guardou algumas roupas da Pitbull, e uma camisa do time de futebol que ele jogava. Alguns bonés foram doados a um grande amigo do filho, os outros o pai faz uso. Vinícius, o irmão da vítima, ficou apenas com uma bermuda para lembrança.O boné sujo de sangue do dia da Chacina, junto a camisa furada da bala, e a sandália, foram recuperados na polícia por Suzana, já que, para ela, tudo custou o suor do filho, e tinha o direito de fazer o que quisesse com as coisas do filho, não o estado. Há uma clara disputa pela memória da Chacina com o Estado.

Suzana mandou algumas peças de roupa para os avós, como o uniforme de trabalho e o aparelho de som que o filho gostava muito de usar, mas, que Suzana não queria que ficasse na sala de sua casa. Primeiramente, essas peças ficaram em sua casa, mas, como o avô sempre quando a visitava pedia para olhar as coisas do neto, ela, assim, resolveu doar parte do acervo para ele. Os documentos de Márcio também foram mandados para a casa dos avós. A cama dele foi tirada do seu quarto e colocada no quarto de Suzana. Ela tem algumas fotos em portaretratos nas estantes da casa. Contudo, ela tem muitas fotos em seu celular e no Tablet que ele deixou. No tablet, além das fotos, têm todas as conversas do aplicativo de mensagemWhatsapp pois a polícia levou o tablet e o celular para investigação e devolveu com todas as conversas recuperadas (inclusive o que foi apagado). $\mathrm{O}$ tablet se tornou um documento a partir que demonstra a inocência do filho (MENESES, 1998).

O celular de Suzana também armazena muitas fotos, para ela, ver as fotos e as coisas "é alimento", ela os vê todos os dias:

Todos os dias. Isso é um alimento, sabia?! Pra mim é um alimento. Não tem assim, dizer assim mesmo: "Ah, não vou olhar aquilo lá". Não, não consigo não olhar as coisas do meu filho. E eu já falei pro Vinícius: 'Vinícius, se eu morrer, acho que vão ter que por tudo dentro do meu caixão. Quero levar' (Suzana). 
Por isso as fotos do perfil do Facebook de Márcio foram salvas, e toda semana depois da morte do filho Suzana postava no perfil da vítima uma foto com uma frase da Bíblia, durante 1 ano, depois desse tempo as postagens começaram a ser mensais. Nesse caso, assim como visto anteriormente nas diversas notícias que David guarda em seu notebook sobre o caso, nota-se que os documentos digitais também se tornam objetos que remetem a vítima, fazendo parte do acervo, por isso, assim como os objetos materiais, eles também são expostos, no entanto, aqui, eles participam de uma exposição virtual que Suzana faz para os amigos de 206 Márcio no Facebook.

Suzana tem vários CDs de festas em que Márcio foi, e escuta para ouvir os DJs anunciarem o nome do filho nas aparelhagens. O conteúdo dos CDs foi posto em um pen drive para ser preservado, e que o pai leva para ouvir nas viagens que faz a trabalho.

A moto de Márcio foi usada apenas por seu irmão que posteriormente sofreu um acidente, depois disso ela ficou guardada. O pai tentou vender, mas Suzana não deixou. Ela não quer que venda e nem que seja usada. Em uma de suas falas ela diz querer que a moto se estrague, pois, para ela, a moto não remete ao filho, já que ela não gostava que ele dirigisse. Ela guarda para ver se destruir paulatinamente pela ação do tempo.

Suzana reflete sobre a política pública de segurança e o estereótipo que foi construído e atribuído aos moradores da periferia das grandes cidades:

\begin{abstract}
Então não prende mais ninguém, sai matando, desce na periferia e sai matando. Eu quero alguém que me faça entender de uma outra lógica. Sinceramente. Porque eu não consigo ver esse conceito de segurança(...) Embora eles pensam que não tem, mas tem na periferia gente de boa índole, que trabalha, que estuda, que faz faculdade, não é todos, não pode generalizar todos, porque eles diziam assim "porque tava com tatuagem, roupa de marca, não sei o quê”. Roupa de marca ele sempre usou, porque ele sempre gostou. Se eu for te buscar para ti ver as roupas, você não vai achar nenhuma camisa comum, a não ser a farda de restaurante, as roupas dele todas eram Pitbull. Aí você julga uma pessoa porque tá vestindo, e sai matando!! (...) (sobre o governador do estado) acredita que quando eu estava no pleno cru da minha dor, virou pra mim e disse assim: "não, talvez deve ser porque ele mora numa zona vermelha. E porque ele tivesse de boné, de camiseta de marca"(...) Ainda tem mais a sociedade. Aqueles que te olham com nojo. "Meu filho não rouba. Meu filho não faz isso". Graças a Deus. Mas não se esquece que tu vai ter outra encarnação e a maldade tá crescendo. Hoje tu ignora, mas tu vai ter neto. (Suzana)
\end{abstract}

Por isso, Suzana guarda objetos que, para ela, descontroem esses estereótipos. A camisa do time que ele jogava que era parte do projeto social dos Megas Camaradas mostra que a vítima era uma pessoa solidária; as roupas da marca Pitbull demostram que julgar uma pessoa pela roupa é uma atitude preconceituosa. 


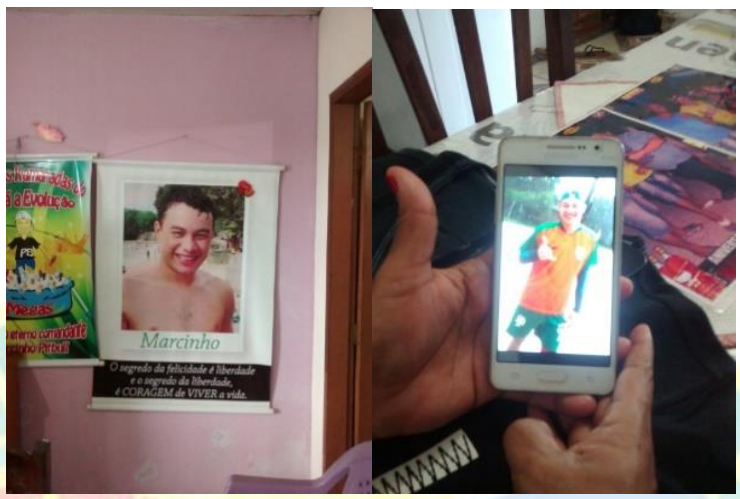

Figura 9 e $10-$

Banner com a foto de Márcio que fica na sala da casa de Suzana à esquerda, e Celular de Suzana com foto de Márcio ao fundo à direita.

Fonte: Andrey Leão.

\section{NOTAS MUSEOLÓGICAS ACERCA DE UMA ESPÉCIE DE MUSEALIZAÇÃO.}

Os objetos deixados pelas vítimas fazem parte do jogo de esquecer e de lembrar que constitui a ideia de memória. A seleção dos objetos pelos familiares liga-se a três grandes narrativas memoriais: 1. a narrativa familiar, quando os objetos falam sobre a experiência mais subjetiva, parental, das lembranças da vida familiar; 2. A narrativa específica da Chacina de Belém, quando os objetos falam sobre a versão da família acerca do evento; e a 3. mais geral, uma narrativa ligada à realidade social, quando os objetos falam sobre a violência e a experiência urbana da periferia que se conecta com a coletividade (jovens, negros, pobres) que partilha da mesma experiência.

O historiador francês Pierre Nora (1993) define a memória como algo vivo, e, quando uma lembrança não está em nossa memória, é necessário criar suportes para rememorá-la, o que ele denomina de "lugares de memória". Ou seja, criamos suportes para que aquilo ainda esteja em evidência, pois, "a memória se enraíza no concreto, no espaço, no gesto, na imagem, no objeto" (Nora, 1993, p. 9). A morte violenta impacta na produção dos acervos compostos por objetos deixados pelas vítimas, que se tornam esses suportes de lembranças, representando/materializando narrativas sobre o familiar morto, sobre a chacina, e sobre a periferia.Eles seriam "objetos de memória”, os patrimônios "que operam na relação simbólica entre algo que se vê, e algo que se deseja ver, mas que está ausente” (Brulon, 2012a, p. 63).

Os objetos/coisas guardados nesses acervos apresentam um ponto de vista sobre os jovens mortos muito diferente do que foi propalado pela mídia, e burila na ideia replicada por 
parcela significativa da sociedade: "bandido bom é bandido morto". Logo, acreditamos que há um potencial evocativo nesses objetos, um valor que Stránský chamou de musealidade $^{6}$,esse valor atribuído pela humanidade ao objeto, valor não material que o permite a viver na esfera do simbólico (Brulon, 2012a).

No campo da museologia, a musealidade se apresenta quando há musealização. Do ponto de vista mais técnico e museal, amusealização é um conjunto de procedimentos que possibilitam que o patrimônio se transforme em herança, na medida em que é alvo de208 preservação e comunicação (Bruno, 2009). Ou, nos termos de outra autora,quando é alvo de procedimentos técnicos, no âmbito dos museus, com início na aquisição, seguido da pesquisa, conservação, documentação e comunicação (Cury, 2005, p. 26).

Acreditamos que o processo de musealização, porém, ocorre nas nossas casas, de uma maneira ou de outra, quando morre um ente da família ocorre seleção, aquisição e salvaguarda de parte de seus objetos. Mais que isso, acreditamos nessamusealização pensando que, para além de procedimentos técnicosmuseais, ela é um fenômeno promove a transformação do objeto, sua suspensão do cotidiano e atribuição de valor especial ${ }^{7}$. Nesse sentido, há um "olhar museológico" em todos os acervos particulares, afetivos, domésticos, que, similar ao que ocorre nos museus, nos faz "estranhar o doméstico, o familiar, e passar a perceber os bens culturais como documentos, testemunhos, fontes de informação, suportes para questões" (Chagas, 2009, p, 68).Os objetos sofrem mudanças de valor ao longo de suas "vidas" (Schärer, 2009).

Aqueles objetos dos jovens mortos na Chacina de Belémque viraram acervo familiar perderam seu uso utilitário e ganharam uma função simbólica. Dois ou mais objetos podem

\footnotetext{
${ }^{6}$ A definição de Stránský sobre musealidade é citada por Klaus Schreiner: "um valor documentário específico dos objetos concretos e perceptíveis da natureza e da sociedade, o valor da evidência autêntica da realidade " (SCHREINER, 1980, p. 39). Maroevic (1997) vê a musealidade como a característica de um objeto material de documentar uma realidade. Ou seja, através da significação do objeto, ele passa carregar valor imaterial, tornando-se documento. Tereza Scheiner diz que a musealidade "é um valor atribuído a certas 'dobras' do Real, a partir da percepção dos diferentes grupos humanos sobre a relação que estabelecem com o espaço, o tempo e a memória, em sintonia com os sistemas de pensamento e os valores de suas próprias culturas. E, portanto, a percepção (e o conceito) de musealidade poderá mudar, no tempo e no espaço, de acordo com os sistemas de pensamento das diferentes sociedades, em seu processo evolutivo" (SCHEINER, 2012, p. 18).

${ }^{7}$ Devalles e Mairesse (2013) conceituam a musealização como uma etapa de separação ou de suspensão, onde os objetos ou as coisas são separados de seu contexto de origem para serem estudados como documentos representativos da realidade que eles constituíam. Peter Van Mensch (1992) diz que a musealização retira o objeto de sua realidade para colocar em outra, o museu. Para Diana Farjallamusealização altera a realidade (da coisa) ao estabelecer um novo contexto de existência (LIMA, 2013). Loureiro vê a musealização como "processos seletivos de caráter infor-comunicacional baseados na agregação de valores a coisas de diferentes naturezas às quais é atribuída a função de documento, e que por esse motivo tornam-se objeto de preservação e divulgação" (LOUREIRO, 2011, p. 2-3).
} 
evocar sentidos semelhantes, provocar narrativas iguais, logo, há uma escolha, e um deles vai para o acervo e os demais para a doação. Como no caso de Dona Auxiliadora que não precisava de mais uma farda de escoteiro para narrar essa lembrança e evocar esse qualificativo constituinte da imagem que ela quer expressar sobre seu neto. Alguns objetos ganharam o uso simbólico e ainda conservam seu uso original. É o caso dos CDs das festas que Márcio, filho de Suzana, frequentava. Eles ainda são usados para tocar as músicas, contudo, eles agora também servem para que ela lembre-se do filho, e ao mesmo tempo209 mostra o quão querido ele era, uma vez que os DJs de aparelhagem anunciarem o nome de "Marcinho Pitibull" nas festas.

\section{CONSIDERAÇÕES FINAIS}

A musealização tem com sentido de preservar e comunicar (Cury, 2005), e para isso, usa-se de diversas etapas (Bruno, 2009) para manter as memórias em evidência, como a seleção, aquisição, exposição. Em alguns casos, como demonstrado aqui, quando os objetos estão em seus contextos, as narrativas provocadas são os elementos mais importantes a serem preservados.

Amusealização no caso dos acervos dos familiares da Chacina é um processo que se dá, a partir de um recorte feito por grupos/pessoas, mudando a natureza do objeto, inserindo numa dimensão simbólica para salvaguardar narrativas memoriais que eles podem despertar. Vanda, Meire, Auxiliadora e Suzana, viram potencial dos objetos (Chagas, 2009) e ao transformarem eles em fontes documentais (Loureiro, 2011), colocando-os na cadeia museológica, objetos museológicos com musealidade, como a musealização faz (Brulon, 2012b). Foram elas as responsáveis pela seleção dos objetos, pelos processos inforcomunicacionais que se desdobraram, atribuíram valor e elaboraram, um acervo com esses objetos, tratando-os como documento, e re-narrando a vida, a morte e a experiência periférica na capital paraense. Foram elas que fizeramesses objetos entrar na esfera do simbólico, ao fazer uso deles como testemunhos de experiências particulares e coletivas.

Vanda, Meire, Dona Auxiliadora e Suzana ainda são responsáveis pela luta por justiça, uma vez que apenas um dos acusados foi preso. Irmãos, netos, sobrinhos, filhos, jovens negros assassinados pela milícia num evento trágico o qual objetos ajudam a contar e elucidar. 
Por fim, a partir de toda experiência e estudos que tivemos durante os 2 anos de pesquisa sobre a Chacina de Belém, a violência urbana, principalmente na periferia, e o modo como o assunto é abordado pela mídia e pela população da capital, reiteramos que os museus da cidade de Belém ainda não cumprem seu papel social de discutir os problemas da sociedade (ICOM, 1999), não se mantêm como espaço de reflexão (Huyssen, 1996) para falar sobre os conflitos sociais. Os museus estão mais preocupados em musealizar objetos inofensivos, que não contam histórias como a da Chacina de Belém, são cúmplices dos210 silenciamentos e das discriminações que certos grupos sofreram e sofrem na cidade. Os museus quando não falam de violência urbana mostram o quão longe estão da realidade social, só resta à Museologia entender que outros acervos, os domésticos, são mais potentes para pensar a vida real.

\section{REFERÊNCIAS}

BARAÇAL, Anaildo Bernardo. Objeto da Museologia: a via conceitual aberta por ZbynekZbyslavStránskýl. Dissertação (Mestrado em Museologia e Patrimônio) - Universidade Federal do Estado do Rio de Janeiro/Museu de Astronomia e Ciências Afins/Programa de Pós graduação em Museologia e Patrimônio, Rio de Janeiro, 2008.

BENJAMIN, Walter. Passagens. Belo Horizonte: Editora UFMG; 2006. 1167 p.

BRULON, Bruno César Soares. Magia, musealidade e musealização: conhecimento local e construção de sentido no Opô Afonjá. Revista Musear, Ouro Preto, v. 1, n. 1, p. 61-75. 2012a.

Máscaras guardadas: musealização e descolonização. Tese (Doutorado em antropologia) - Programa de Pós-Graduação em Antropologia. Universidade Federal Fluminense, Niterói. 2012b.

Novas tendências em Museologia: ressonância, agência e canibalismo. In: ACTAS

DEL XXII ENCUENTRO DEL ICOFOM LAM : NUEVAS TENDENCIAS PARA LA MUSEOLOGÍA EN LATINOAMÉRICA / 1A EDICIÓN ESPECIAL - Cidade Autónoma de Buenos Aires: ICOM Argentina, p. 240-259. 2014.

Paisagens culturais e os patrimônios vividos: vislumbrando a descolonização, para uma musealização consciente. Museologia e Patrimônio - Revista Eletrônica do Programa de PósGraduação em Museologia e Patrimônio - Unirio | MAST - vol.10, no1, p, 65-86, 2017.

BRUNO, Cristina. Formas de Humanidade: Concepção e desafios da musealização. Cadernos de Sociomuseologia, [S.l.], ISSN 1646-3714, v. 9, $\quad$ n. $\quad 9$, 2009. Disponível em: <http://revistas.ulusofona.pt/index.php/cadernosociomuseologia/article/view/293>. Acesso em: 16 jan. 2018. 
CHAGAS, Mário de Souza. Há uma gota de sangue em cada museu: a ótica museológica de Mário de Andrade. Chapecó, São Paulo: Editora Argos, 2006. 135 p.

Millôr Fernandes e a Nova Museologia. Cadernos de Sociomuseologia,

ISSN $1646-3714 \quad$ v. $\quad 2, \quad$ n. $2.2009 . \quad$ Disponível em:

$<$ http://revistas.ulusofona.pt/index.php/cadernosociomuseologia/article/view/536>. Acesso em: 17 jan. 2018.

CURY, Marília Xavier. Museu, filho de Orfeu, e musealização. In: ENCUENTRO REGIONAL DO ICOFOM-LAM, 8. Coro, Venezuela. Anais, p. 50-55, 1999. Exposição: concepção, montagem e avaliação. São Paulo: Editora Annablume, 2005. 146 p.

DESVALÉES, André; MAIRESSE, François. Conceitos-chave de Museologia. Bruno Brulon Soares e Marília Xavier Cury, tradução e comentários. São Paulo: Comitê Brasileiro do Conselho Internacional de Museus: Pinacoteca do Estado de São Paulo: Secretaria de Estado da Cultura, 2013. 100 p.

LIMA, Diana F. C. Museologia, Campo disciplinar da musealização e fundamentos de inflexão simbólica: 'tematizando' Bourdieu para um convite à reflexão. Museologia e Interdisciplinaridade. Vol. 4, p. 48-61, 2013.

Museologia-Museu e Patrimônio, Patrimonialização e Musealização: ambiência de comunhão. Boletim do Museu Paraense Emílio Goeldi. Ciências Humanas. Belém, v. 7, n. 1, p. 31$50,2012$.

GONÇALVES, José Reginaldo Santos. Antropologia dos objetos: coleções, museus e patrimônio. Rio de Janeiro: Editora do Instituto do Patrimônio Histórico e Artístico Nacional (IPHAN), 2007. 251 p.

GREGOROVÁ, Anna. La muséologie: science ou seulementtravail pratique dumusée?

MuseologicalWorkingPapers. ICOFOM. Estocolmo, n.1, p. 19-21, 1980.

HALBWACHS, Maurice. A Memória Coletiva. Tradução de Beatriz Sidou. São Paulo: $2^{\mathrm{a}}$ ed. Ed. Centauro, 2013. 224 p.

HUYSSEN, Andrea. Memória do Modernismo. Tradução Patrícia Farias. Rio de Janeiro: Editora da UFRJ, 1996. $255 \mathrm{p}$.

LEITE, M. M. Retratos de Família: Leitura da Fotografia Histórica. São Paulo: Editora da Universidade de São Paulo, 1993. 200 p.

LOUREIRO, Maria Lucia N. M. "Preservação in situ X ex situ: reflexões sobre um falso dilema". In: 3. ${ }^{\circ}$ SEMINÁRIO IBEROAMERICANO DE MUSEOLOGIA, Madrid, Espanha, 2011. Disponível em: https://repositorio.uam.es/bitstream/handle/10486/11607/57448_16.pdf?sequence=1

LOUREIRO, João de Jesus dos Santos; FERREIRA JUNIOR, Sérgio do Espirito Santo; COSTA, Alda Cristina. Polícia, mocinhos e vilões: informalidade no Twitter: \#ChacinaEmBelém. In: CONGRESSO BRASILEIRO DE CIÊNCIAS DA COMUNICAÇÃO, 38, 2015, Rio de Janeiro, RJ, 2015. 
MAROEVIČ, Ivo. O papel da musealidade na preservação da memória. In: SIMPÓSIO ANUAL MUSEOLOGIA E MEMÓRIA. ICOFOM. Paris, Conselho Internacional de Museus/ICOM: Comitê Internacional de museologia/ICOFOM. 1997.

MENESES, U.T.B. de. Do teatro da memória ao laboratório da História: a exposição museológica e o conhecimento histórico. In: ANAIS DO MUSEU PAULISTA: HISTÓRIA E CULTURA MATERIAL. São Paulo: Museu Paulista-USP, v. 2. p. 9-42, 1994. Memória e cultura material: documentos pessoais no espaço público. Estudos históricos. Revista Estudo Históricos. Rio de Janeiro, v. 11, n. 21, p. 89-103, 1998.

MENSCH, Peter Van. Towards a methodology of museology. University of Zagreb: PhD thesis. Zagreb, 1992.

MESA REDONDA DE SANTIAGO DO CHILE - 1972. Cadernos de sociomuseologia, v. 15, n. 15, Porto, p. 111- 121, 1999.

MILLER, Daniel. Trecos, Troços e Coisas: Estudos antropológicos sobre a Cultura Material;

Tradução: Renato Aguiar. Rio de Janeiro: Editora Zahar, 2013. 248 p.

MOREIRA, R. N. P. História e Memória: Algumas Observações. Revista História Catarina, Lages. Santa Catarina, p. 66 - 69, 2011.

NORA, Pierre. Entre Memória e História: a problemática dos lugares. Projeto História: Revista de Estudos Pós-Graduados em História e do Departamento de História da PUC-SP. p. 7-28. 1993.

PARÁ. Assembleia Legislativa Estado do. Comissão Parlamentar de Inquérito para apuração da atuação de grupos de extermínio e milícias no Estado do Pará: relatório final. Belém, Pará, 2015. Disponível em: <http://www.movimentodeemaus.org/data/material/RELATORIO-FINAL-CPI-dasMilicias-versao-de-entreega-na-grafica3.pdf>.

POLLAK, Michael. Memória, esquecimento, silêncio. Estudos Históricos, Rio de Janeiro, vol. 2, n.3, p. 3-15, 1989

SCHÄRER, Martin. Things + ideas + musealization = heritage a museological approach. Revista Museologia e Patrimônio, v. 2, n. 1, Rio de Janeiro, p. 85-89, 2009.

SCHEINER, Tereza. Repensando o museu integral: do conceito às práticas. Boletim do Museu Paraense Emílio Goeldi. Belém, v. 7, n. 1, p. 15-30, 2012. Disponível em: http://pablo.deassis.net.br/wp-content/uploads/Hist\%C3\%B3ria-e-Mem\%C3\%B3ria.pdf.

SCHREINER, Klaus. Museology: science or just practical museum work? MuseologicalWorkingPapers, 1. p. 39-41, 1980.

SELIGMANN-SILVA, Márcio. Testemunho e a política da memória: o tempo depois das catástrofes. Projeto História, São Paulo, p. 71-98, jun. 2005

STALLYBRASS, Peter. O Casaco de Marx: roupas, memória, dor. Rio de Janeiro: Ed. Autêntica. 2016. $112 \mathrm{p}$. 